\title{
МЕЖДУНАРОДНАЯ ГУМАНИТАРНАЯ КОМИССИЯ ПО УСТАНОВЛЕНИЮ ФАКТОВ: ДЕЙСТВУЮЩЕЕ РЕГУЛИРОВАНИЕ И ПРИЧИНЫ БЕЗДЕЙСТВИЯ
}

Аннотация. Статья представляет собой комментарий к статье 90 Дополнительного протокола к Женевским конвенциям 1949 года, касающегося защиты жертв международных вооруженных конфликтов, 1977 г. Автором проведен детальный анализ правового регулирования организации и деятельности Международной гуманитарной комиссии по установлению фактов. Подробно освещены порядок формирования, состав, компетенциия, основания компетенции, процедура и некоторые другие аспекты функционирования Комиссии, обращено внимание на возможность расследовать нарушения, совершенные $в$ период немеждународных вооруженных конфликтов, а также на полномочие оказывать добрые услуги. При подготовке работы использованы следующие методы: всеобщий (диалектический), общенаучные (аналитический, синтетический, функииональный, системный), специально-юридические (формально-юридический, сравнительно-правовой). На сегодняшний день Комиссия является бездействующей. Ключевой причиной, обусловливающей ее бездействие на протяжении более двадиати лет, является несоответствие между ее правовыми характеристиками и иелью функиионирования. Задуманная как механизм обеспечения выполнения международного гуманитарного права, Комиссия, тем не менее, стала частью системы разрешения споров. Ее функиии более соответствуют «гроиианской» модели международных обязательств, нежели чем «кантианской». Она действует в интересах отдельных государств, находящихся в конфликте, но не в интересах международного сообщества. Содействовать выполнению международного гуманитарного права Комиссия в силах лишь постольку, поскольку стороны конфликта принимают меры в отношении друг друга на основе ее доклада. Остальные государства и международные организации остаются вне данного процесса. Автором предложены меры по решению проблемы.

Ключевые слова: Установление фактов, международнаягуманитарнаякомиссияпоустановлениюфак, международное расследование, обеспечение выполнения права, международное гуманитарное право, разрешение международных споров, следственная комиссия, серьезные нарушения, инцидент в Кундузе, добрые услуги.

Abstract: The paper presents a commentary on Article 90 of the Additional Protocol to the Geneva Conventions of 1949 and relating to the Protection of Victims of International Armed Conflicts, 1977. The author made a detailed analysis of the legal regulation of the organization and functioning of the International Humanitarian Fact-Finding Commission. Details covered the formation, composition, competence, grounds of competence, the procedure and some other aspects of the functioning of the Commission. The author gave special consideration to the opportunity to investigate the violations committed during non-international armed conflicts, as well as the right to provide good offices. During the course of this research the author used the following methods: dialectical, analytical, synthetic, functional, systematic, legalistic and comparative. To date, the Commission is inactive. A key reason is the contradiction between 
its legal characteristics and purpose of the operation. Conceived as a mechanism to ensure the implementation of international humanitarian law, the Commission, however, is a part of the system of settlement of disputes. Its functions are more appropriate to Grotian model of international obligations, rather than to Kantian one. It operates in the interests of individual conflicting states, rather than in the interest of the whole international community. The Commission is able to ensure the implementation of international humanitarian law insofar as the parties to the conflict take measures in relation to each other on the basis of its report. Other countries and international organizations remain outside this process. The author suggested some solutions of the problem.

Keywords: Geneva Convention, International Humanitarian Fact-Finding Commission, Ensuring legal order, International investigation, International disputes resolution, International humanitarian law, Investigative commission, Serious violations, Kunduz airstrike, Good deeds.

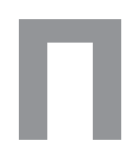

роцесс применения (реализации) норм права начинается с анализа фактических обстоятельств. Неопределенность факта делает выбор норм права и их применение затруднительными. В международных отношениях это создает плодотворную почву для разногласий и споров, лишает международное сообщество возможности адекватно реагировать на происходящие события. Напротив, полное и точное выяснение фактов может способствовать уменьшению амплитуды политических взглядов на ту или иную ситуацию и повышению эффективности международного права. Особенно это важно применительно к действию международного гуманитарного права (МГП), невыполнение норм которого влечет за собой наиболее трагические последствия. По утверждению И.И. Лукашука, «прогресс средств информации привел к такому положению, когда скрыть международное правонарушение стало практически невозможно» [26, С. 85]. Однако с минимизацией возможностей сокрытия международного правонарушения обострилась проблема поиска истинного варианта событий и определения подлинности доказательств.

Положительным решением проблемы могли бы стать международные расследования нарушений МГП. Сообществом государств была учреждена Международная гуманитарная комиссия по установлению фактов (Комиссия), призванная проводить такие расследования на постоянной основе. Однако практическое воплощение идеи постоянного органа по международным расследованиям оказалось весьма затруднительным. Несмотря на то, что нормы о деятельности Комиссии были согласованы государствами еще в 1977 году, ее формирование и начало функционирования ставились под условие признания компетенции не менее чем двадцатью государствами-участниками Дополнительного Протокола I к Женевским конвенциям (Протокол) [2]. Это условие было выполнено лишь в 1990 году. В 1991 году Федеральный совет Швейцарии как депозитарий Протокола, организовал конференцию в Берне, в которой приняли участие представители 20 государств, признавших компетенцию Комиссии. Тогда в ее состав были избраны первые 15 членов. Но «действующей» Комиссия стала после того как в 1992 году приняла внутренний регламент [19, Р. 5], [4]. С тех пор, однако, она не функционирует [10, Р. 442].

\section{Порядок формирования и состав}

Комиссия - это орган, состав которого формируется на выборной основе (иной порядок применяется тогда, когда в период 
между выборами образуется «непредвиденная вакансия». В таком случае Комиссия сама заполняет ее путем голосования действующих членов) [пп. е) п. 1 ст. 90 Протокола, правило 5 Регламента]. Выборы ее членов организуются депозитарием и проводятся каждые пять лет на конференции представителей государств-участников Протокола, признавших компетенцию Комиссии. Процедура выборов состоит из двух этапов. Сначала формируется список лиц, в который каждое государство вправе внести одну кандидатуру. Затем проводится тайное голосование и избираются 15 членов Комиссии. Во время выборов государства должны следить за тем, чтобы в Комиссии в целом было обеспечено «справедливое географическое представительство» [пп. d) п. 1 ст. 90 Протокола] и чтобы кандидаты обладали «высокими моральными качествами и признанной беспристрастностью» [пп. a), d) п. 1 ст. 90 Протокола]. Других требований к членам Комиссии, в особенности к их профессии и профессионализму, статья 90 Протокола не предъявляет. Тем не менее, очевидно, что признанной беспристрастностью и высокими моральными качествами не должна исчерпываться личность экспертов. Определенно они должны быть профессионалами, иметь знания и умения, позволяющие им выполнять следственную работу любого уровня сложности. Важно, чтобы они обладали стрессоустойчивостью, способностью работать в условиях ограниченности во времени и средствах. Что касается их профессий, то они должны позволять Комиссии достоверно и полно устанавливать факты нарушений МГП. В ее составе желательно присутствие военных специалистов, медицинских экспертов, следователей. Среди членов должны быть также юристы, поскольку Комиссия сталкивается с необходимостью решать правовые вопросы (определение объема собирае- мых сведений, границ мандата и т.д.) [16, Р. 445-446], [15, Р. 175], [8, Р. 1045]. Однако их число не должно превышать число специалистов, профессионально занимающихся установлением фактов. Текущий же состав Комиссии более чем на 2/3 состоит из юристов-международников [17].

Государства могут контролировать, чтобы эксперты обладали необходимыми качествами, только в процессе выборов. В остальное время за этим должна следить сама Комиссия. Если в пределах срока полномочий экспертов у нее возникнут обоснованные сомнения в их нравственности и беспристрастности (в связи с деятельностью или публичными заявлениями), то она может решить вопрос о принятии «должных мер» [правило 3 Регламента]. Перечень, порядок и последствия применения таких мер в Протоколе и Регламенте не отражены.

Принцип справедливого географического представительства являет собой дань традиции формирования международных органов и, вероятно, служит гарантией беспристрастности членов Комиссии при проведении расследований в любом регионе мира. В Протоколе принцип имеет двойное закрепление. Он должен соблюдаться на стадии выборов членов Комиссии, а также при назначении Председателем Комиссии членов Палаты [пп. d) п. 1, пп. а) п. 3 ст. 90 Протокола]. В литературе сложилось широкое понимание пределов справедливого географического представительства. Отмечается, что отбор членов не должен зависеть от того, признало ли то или иное государство компетенцию Комиссии, является ли оно участником Женевских конвенций и Протокола [18, Р. 542-543]. Разумность такого подхода обусловлена тем, что Комиссия компетентна проводить расследования не только по запросам государств, предварительно признавших ее компетенцию и участвовавших в выборах 
экспертов, но и тех, которые признают компетенцию для конкретного расследования (ad hoc). Неясным остается вопрос о содержании принципа. Так, не исключена возможность пребывания в качестве членов Комиссии нескольких граждан одного государства, поскольку требования к гражданству кандидатов не предъявляются. В связи с этим предлагаются различные пропорции представительства в зависимости от количества государств на каждом континенте, от различий правовых систем и т.д. Хотя членство в Комиссии нескольких граждан одного государства явно не соответствует принципу справедливого представительства, закрепление строгих критериев «справедливости» способно ограничить волю государств в выборе тех кандидатов, которые обладают признанной беспристрастностью, высокими моральными и другими качествами, непосредственно значимыми для работы Комиссии.

После избрания члены Комиссии «выступают в своем личном качестве» [пп. с) п. 1 ст. 90 Протокола], т.е. не являются представителями государств, следовательно, в своей работе должны руководствоваться не интересами последних, а целью проведения объективного и беспристрастного расследования. Дополнительная гарантия этого правила состоит в том, что все расследования проводятся Палатой, в состав которой не могут входить граждане «ни одной из сторон, находящихся в конфликте» (если иное не установлено специальным соглашением сторон) [пп. а) п. 3 ст. 90 Протокола]. Кроме того, члены Комиссии не должны принимать указания каких-либо лиц или организаций [п. 1 правила 1 Регламента].

\section{Компетенция}

Направления деятельности Комиссии указаны в пп. с) п. 2 ст. 90 Протокола:
- расследование любых фактов, предположительно представляющих собой «серьезное нарушение, как оно определяется Женевскими конвенциями и Дополнительным Протоколом I, или другое серьезное нарушение Конвенций или Протокола» (но не Дополнительного Протокола II);

- оказание добрых услуг конфликтующим сторонам для восстановления уважительного отношения к Женевским Конвенциям и Дополнительному Протоколу I.

Объектом расследования являются факты нарушений норм Женевских конвенций и Протокола. Есть два типа таких нарушений. В английском языке они обозначаются следующим образом: «grave breaches and other serious violations». В русском языке эти два типа объединены единым термином «серьезные нарушения».

К первому типу нарушений («grave breaches») относятся те, которые определены в статье 50 I Женевской конвенции, статье 51 II Женевской конвенции, статьях 13 и 130 III Женевской конвенции, статье 147 IV Женевской конвенции, статьях 11 и 85 Дополнительного протокола I. Например, это преднамеренное убийство, пытки и бесчеловечное обращение, преднамеренное причинение тяжелых страданий или серьезного увечья, нанесение ущерба здоровью, незаконное депортирование.

Ко второму типу («other serious violations») относятся все остальные серьезные нарушения, не нашедшие прямого отражения в нормах Женевских конвенций и Протокола [8, Р. 1033]. Э. Куссбах среди таких называет невыполнение статей 49, 50, 129 и 146 Женевских конвенций, которые обязывают государства принять законодательство, необходимое для обеспечения эффективных уголовных наказаний для лиц, совершивших или приказавших совершить те или иные серьезные нарушения [15, 
Р. 176]. По мнению автора, отличие состоит в том, что нарушения второго типа влекут ответственность только государств, тогда как нарушения первого типа влекут также индивидуальную ответственность $[15$, Р. 176]. Исходя же из норм Протокола, между ними нельзя провести содержательных различий. Поэтому желательно на нормативном уровне установить если не перечень, то хотя бы критерии определения нарушений второго типа, поскольку от этого зависят пределы компетенции Комиссии.

Немаловажным является вопрос о том, вправе ли Комиссия проводить расследования нарушений, совершенных в период немеждународных вооруженных конфликтов. Положения статьи 90 Протокола прямо не предусматривают такой возможности. С другой стороны, в пп. d) п. 2 статьи 90, где закреплено основание компетенцию Комиссии ad hoc, использованы термины «сторона, находящаяся в конфликте» и «заинтересованная сторона», которые содержательно шире термина «высокая договаривающаяся сторона» из пп. а) п. 2 статьи 90. Разность терминологии в данном случае позволяет некоторым авторам распространять компетенцию Комиссии по запросам ad hoc на конфликты с участием сторон, не являющихся государствами. Целесообразность такого расширительного толкования может быть обоснована теми «страшными нарушениями», которые совершаются во время многих внутренних вооруженных конфликтов [12, P. 106-107], а также тем, что количество немеждународных вооруженных конфликтов превышает число международных [20, Р. 2]. Кроме того, это толкование соответствует исходному предназначению Комиссии - обеспечивать выполнение МГП, которое должно применяться и в периоды немеждународных конфликтов. Сама Комиссия поддерживает данный подход [19, Р. 2], выдвигая в качестве главного условия согласие всех сторон [20,
P. 1]. Между тем, Дополнительный Протокол I посвящен защите жертв международных вооруженных конфликтов, и его положения следует толковать с учетом данного обстоятельства. Поэтому действующее регулирование деятельности Комиссии едва ли предоставляет ей правовую возможность действовать в случае немеждународных конфликтов.

Отдельным направлением деятельности Комиссии является оказание добрых услуг. Задача добрых услуг состоит в том, чтобы «склонить государства, между которыми возник спор, к урегулированию его при помощи какого-либо мирного средства, в частности содействовать установлению между ними прямых дипломатических переговоров и контактов» [27, С. 470]. Наличие у Комиссии такого полномочия не соответствует общей цели ее деятельности - обеспечивать выполнение МГП - и может негативно влиять на проведение расследований. Кроме того, данная деятельность практически не имеет нормативного регулирования и осуществляется на конфиденциальной основе [21, Р. 9]. В этой связи представляется, что добрые услуги являются побочным направлением деятельности и в перспективе должны быть изъяты из компетенции Комиссии.

\section{Основания компетенции}

Чтобы получить доступ к Комиссии, государство должно выразить двойное согласие: во-первых, ратифицировать Дополнительный Протокол I, во-вторых, отдельным актом признать компетенцию Комиссии. Признание может быть как предварительным, так и ad hoc.

1. Предварительное признание компетенции (юрисдикции) принято в практике Международного Суда Организации Объединенных Наций (OOH) и других судебных и квазисудебных органов [25, 
С. 671-672]. Для его действия необходимо специальное заявление, сделанное как во время подписания, ратификации Протокола или присоединения к нему, так и в «любое последующее время» [пп. а) п. 2 ст. 90 Протокола]. В отличие от близких положений Статута Международного Суда ООН, в статье 90 Протокола не указаны разновидности заявлений: безусловные, под условием взаимности и на определенное время $[1, \Pi .3$ ст. 36 Статута Международного Суда $\mathrm{OOH}]$. Вопрос о возможности условных заявлений является открытым [5, Р. 543].

Основанная на принципе взаимности [28, С. 807], предварительно признанная компетенция распространяется только на те государства, которые сделали аналогичные заявления [пп. а) п. 2 ст. 90 Протокола]. Используя положения теории международного правосудия, можно отметить, что за счет односторонних заявлений Комиссия имеет квазиобязательную юрисдикцию: «обязательную» в том смысле, что в отношении государства, сделавшего заявление, может быть проведено расследование без необходимости получения его специального согласия; «квази» в том смысле, что такая юрисдикция устанавливается свободным волеизъявлением государства [29, С. 136].

На сегодняшний день признали компетенцию Комиссии Россия, большинство стран Евросоюза и Южной Америки, Канада, Австралия и часть стран Африки - всего 76 государств. Не признали США, почти все азиатские и большинство африканских государств [23].

2. Вторым основанием компетенции Комиссии является просьба (запрос) одной стороны, находящейся в конфликте, скрепленная согласием другой заинтересованной стороны или сторон. И запрос, и согласие имеют силу лишь в отношении конкретной ситуации. Поэтому признание компетенции Комиссии с обеих сторон действует ad hoc.
В литературе обосновывается возможность сделать запрос о проведении расследования также теми государствами, которые не участвуют в конфликте [8, Р. 1044], [12, Р. 107], [5, Р. 543]. Аргументами в пользу этой позиции выступают требования защиты жертв, представляющие интерес для всего человечества, а также обязанность «заставлять соблюдать» право вооруженных конфликтов [25, С. 672-673]. Контраргументом служит то, что государство может сделать запрос о проведении расследования, «основываясь на политической выгоде или дружественных отношениях, которые в международном гуманитарном праве недопустимы» [18, Р. 267-268]. Представляется, что более удачным было бы инициирование таких расследований главными органами Организации Объединенных Наций, которая призвана служить в интересах всего человечества и меньше отдельных государств подвержена политической ангажированности. Между тем, такое решение уже выходит за пределы действующего регулирования и является предложением de lege ferenda.

\section{Работа Комиссии}

Время от времени Комиссия проводит собрания для обсуждения текущих вопросов, участия экспертов в мероприятиях и планов на будущее. Собрания проводятся настолько часто, насколько это необходимо, но не реже одного раза в год [п. 1 правила 14 Регламента]. Заседания являются закрытыми, обеспечивается конфиденциальность обсуждений. Кроме членов Комиссии, только сотрудники Секретариата, переводчики и персонал могут присутствовать на них, если Комиссия не решит иначе [правило 18 Регламента].

Общий порядок проведения расследований изложен в статье 90 Протокола. При этом заинтересованные стороны могут 
отойти от него путем соглашения. Часть норм детализирована в Регламенте. Все расследования проводятся Палатой в составе семи членов, пять из которых состоят в Комиссии и назначаются ее Председателем после консультации со сторонами конфликта, а два других действуют ad hoc и назначаются самими сторонами. В каждую из указанных групп не могут входить граждане государств, находящихся в конфликте [пп. а) п. 3 ст. 90 Протокола]. По всей видимости, специальные члены Палаты могут быть как избраны из состава Комиссии, так и приглашены со стороны [18, Р. 265].

Присутствие в Палате членов ad hoc может быть подвергнуто критике. Несмотря на то, что они вносят вклад в поддержание «атмосферы доверия» [8, Р. 1048], они не проходят процедуру общих выборов, следовательно, контроль в отношении их «высоких моральных качеств и признанной беспристрастности» снижен. Может оказаться, что в процессе расследования эксперты ad hoc будут ориентироваться на интересы государств, их назначивших, а не на объективность итогов расследования.

Первоначально просьба о проведении расследования направляется в Секретариат, который затем передает ее Председателю [п. 1 правила 20 Регламента]. Председатель Комиссии безотлагательно сообщает об этом заинтересованным сторонам и устанавливает срок для учреждения Палаты [п. 1 правила 21 Регламента]. Если сторона конфликта не успевает назначить специального члена Палаты в течение этого срока, то его назначает Председатель [пп. b) п. 3 ст. 90 Протокола]. Это необходимо для обеспечения оперативности расследования. Если Комиссия получает просьбу о расследовании в порядке пп. d) п. 2 ст. 90 Протокола, и если согласие другой стороны еще не получено, то она направляет копию просьбы этой стороне с запросом о даче согласия [п. 6 пра- вила 20 Регламента]. Председатель при этом указывает на ее право представить в установленный срок возражения относительно приемлемости просьбы. Установление такого срока, однако, не влияет на момент начала работы Комиссии [п. 1 правила 21 Регламента].

\section{Процесс расследования}

Процесс расследования урегулирован статьей 90 Протокола довольно слабо. Как указано в Регламенте, общие или специальные инструкции или руководящие принципы, касающиеся расследования, которыми следует руководствоваться Палате, устанавливаются Комиссией [правило 26 Регламента].

Приступая к расследованию, Палата предлагает сторонам, находящимся в конфликте, оказать ей содействие и представить доказательства. Характер данной формулировки означает, что стороны могут принять, отвергнуть или проигнорировать это предложение. Во всяком случае, Палата может искать другие доказательства и вести расследование на месте (in loco) [пп. a) п. 4 ст. 90 Протокола]. Относительно последнего положения А. Мохтар задает справедливые вопросы о том, обязаны ли стороны обеспечивать Палате доступ к месту расследования и обязаны ли они сотрудничать с ней $[18$, Р. 298]?

Давая утвердительный ответ на первый вопрос, автор обосновывает его тем, что если государство признало компетенцию Комиссии в порядке пп. а) п. 2 ст. 90 или согласилось на проведение расследования в порядке пп. d) п. 2 ст. 90 (не оговорив в специальном соглашении запрет доступа Палаты на свою территорию), то оно связано всеми положениями статьи 90 Протокола и поэтому обязано обеспечить доступ. Дальше А. Мохтар пишет, что с обязанностью обе- 
спечить доступ экспертов тесно связана и обязанность сотрудничества. Она состоит в создании всех необходимых условий для деятельности Палаты (в частности, в сопровождении ее квалифицированным персоналом), а также предполагает недопустимость создания препятствий расследованию (например, путем запугивания или преследования свидетелей и их родственников), что вытекает из принципа добросовестности.

Положительная сторона этой аргументации в том, что она нацелена на облегчение работы Комиссии и достижение ее целей. Между тем, она может оказаться недостаточно убедительной для государств, на которых возлагает обязанности, напрямую не закрепленные в тексте Протокола. Если обязанность государств обеспечить доступ членам Палаты и не препятствовать им при проведении расследований на месте выводится из права Палаты «проводить расследование положения на месте» логически, то обязанность позитивного сотрудничества может быть сформулирована только при помощи систематического толкования на основе принципа добросовестности. Такую тонкую связь юридических аргументов легко не заметить в период вооруженного конфликта. Государства для защиты своей позиции могут исходить из формулировок статьи 90 Протокола и выступать за толкование в пользу минимального ограничения своих прав. Поскольку оставление столь важного вопроса на усмотрение толкователя нерационально, необходимо закрепить обязанность государств обеспечивать доступ Палате и обязанность сотрудничать с ней в тексте Протокола.

\section{Итоги расследования}

По окончании расследования Палата незамедлительно сообщает о его результатах Комиссии [п. 7 правила 27 Регламента]. Все собранные доказательства доводятся до сведения заинтересованных сторон, которые имеют право представлять Комиссии замечания в отношении этих доказательств и оспаривать их [пп. b), с) п. 4 ст. 90 Протокола].

Расследование может не увенчаться успехом. Во-первых, сторона вправе отказаться от расследования. Согласно Регламенту такой отказ имеет силу, только если получено согласие других сторон конфликта. При этом его действие не распространяется на обязанность возместить расходы Комиссии [п. 6 правила 21 Регламента]. Во-вторых, Палата может не выработать объективное и беспристрастное заключение ввиду недостаточности доказательств. В таком случае Комиссия сообщает сторонам причины этого [пп. b) п. 5 ст. 90 Протокола] или предписывает Палате провести дополнительное расследование [п. 9 правила 27 Регламента].

В случае если Палате удалось установить те или иные факты нарушений, то по итогам расследования Комиссия представляет заинтересованным сторонам доклад о них «с рекомендациями, которые она считает необходимыми» [пп. а) п. 5 ст. 90 Протокола]. В частности, она может рассмотреть вопрос об оказании сторонам добрых услуг [п. 1 правила 28 Регламента], обосновать меры дальнейшего урегулирования спора, что придает ей некоторые черты посредника [8, Р. 1050].

Комиссия не сообщает публично о своих заключениях, если только все стороны, находящиеся в конфликте, не попросят ее об этом [пп. с) п. 5 ст. 90 Протокола]. Необходимо именно коллективное обращение к Комиссии, «простого согласия недостаточно» [15, Р. 178]. Все лица, вовлеченные в процесс расследования, обязаны не разглашать собранные Палатой данные [правило 29 Регламента]. Представляется, что конфиденциальность отчетов является ключевым недостатком Комиссии в деле обеспечения выполнения 
МГП. Она лишает международное сообщество возможности знать нарушителя и влиять на него. С другой стороны, принцип конфиденциальности может рассматриваться как преимущество, если усматривать предназначение Комиссии в разрешении межгосударственных споров о фактах.

\section{Финансирование и прочие вопросы}

Для того чтобы Комиссия могла осуществлять свои функции, необходимы финансовые средства. Расходы могут производиться как на содержание Комиссии (административные расходы), так и на проведение конкретных расследований Палатой. Административные расходы идут на организацию собраний Комиссии, довольствие сотрудникам секретариата и самих членов, транспортные расходы и т.д. Они покрываются за счет взносов государств, признавших ее компетенцию, и за счет добровольных взносов. Расходы на проведение расследований Палатой несет сторона конфликта, которая обращается с просьбой о проведении расследования. При этом она авансирует необходимые средства на покрытие всех расходов Палаты, а противоположная сторона возмещает ей половину [п. 7 ст. 90 Протокола]. Размер предполагаемых расходов на расследование определяется Председателем Комиссии по согласованию с Секретариатом [правило 22 Регламента]. В механизме финансирования Комиссии можно проследить два недостатка. Обязанность государств покрывать часть административных расходов является одной из причин непризнания компетенции Комиссии. Кроме того, государство может отказаться возмещать расходы Палаты на проведение расследования, что автоматически его остановит.

Административную помощь в выполнении функций Комиссии оказывает де- позитарий [пп. f) п. 1 ст. 90 Протокола], а именно Федеральный совет Швейцарии. Официальными и рабочими языками являются английский и французский [правило 13 Регламента]. Местопребывание Комиссии г. Берн, Швейцария [правило 11 Регламента].

\section{Взаимодействие с ООН}

В 2009 году Комиссии был присвоен статус наблюдателя Генеральной Ассамблеи $\mathrm{OOH}$ [3]. Что касается роли органов $\mathrm{OOH}$ в ее деятельности, то Комиссия придерживается того мнения, что Совет Безопасности, Генеральная Ассамблея и Генеральный Секретарь ООН могут «настоятельно рекомендовать» сторонам конфликта дать согласие на проведение расследования. В отдельных случаях Совет Безопасности может использовать полномочия по принуждению в соответствии с Уставом ООН $[19$, Р. 2]. Важно учитывать, что хотя эти предложения перспективны, они не основаны на действующем регулировании - статья 90 Протокола не предусматривает такой формы деятельности Комиссии. Для того чтобы претворить их в жизнь, необходимо разработать порядок и правовые основы взаимодействия Комиссии и $\mathrm{OOH}$.

\section{Неактивность}

Несмотря на то, что Комиссия существует юридически и фактически, она ни разу не проводила расследования нарушений МГП и не оказывала конфликтующим сторонам добрые услуги. Этот факт кладется в основу критики в адрес Комиссии и вызывает наибольшую озабоченность ее членов. С момента создания деятельность Комиссии сводилась к таким вопросам, как поиск оборудования для расследований на месте, составление списков специальных экспертов, распространение сведений и т.д. [7, 
P. 490]. Эксперты принимали активное участие в конференциях и семинарах по проблемам МГП. В отсутствие реальных дел Комиссия проводила тренировочные расследования по материалам вымышленных ситуаций [20, Р. 2]. Государства обращались к Комиссии за разъяснениями о принципах и порядке расследований, контактировали по вопросу о возможности привлечения ее для разрешения споров и в других случаях.

В октябре 2015 года к Комиссии обратилась международная неправительственная организация «Врачи без границ» с просьбой провести расследование обстоятельств обстрела госпиталя в афганском городе Кундузе. В результате атаки авиацией США в ночь на 3 октября 2015 года было разрушено здание травматологического центра, убиты 14 членов медицинского персонала, 24 пациента и 4 добровольца-смотрителя [14]. Президент США принес извинения за произошедший инцидент, руководство НАТО и США выразили готовность провести внутреннее расследование, однако согласие на инициирование международного расследования Комиссией получено не было. «Врачи без границ» организовали сбор подписей в поддержку петиции, призывающей власти США выразить такое согласие. Более 540 тысяч человек по всему миру ее поддержали [13]. Тем не менее, реакции со стороны властей США не последовало. Стоит отметить, что расследование инцидента с госпиталем в Кундузе не было начато Комиссией в силу нескольких обстоятельств. Во-первых, заявитель («Врачи без границ») не был уполномоченным субъектом. Во-вторых, ни Афганистан, ни США заблаговременно не признали компетенцию Комиссии. В-третьих, ни одно из двух государств не согласилось на расследование ad hoc. Таким образом, возможность активации Комиссии в свете октябрьской бомбардировки госпиталя не была реализована.
Представляется, что исходными предпосылками бездействия Комиссии служат два обстоятельства.

I. Характеристики Комиссии не соответствуют цели ее функционирования.

Комиссия была задумана как механизм обеспечения выполнения МГП. Эта цель закреплена во внутреннем регламенте Комиссии [Преамбула Регламента] и признана ей самой в ряде отчетов. Между тем, ряд правовых характеристик Комиссии делают достижение указанной цели маловероятным. К таким параметрам относятся следующие.

1. Консенсуальная основа функционирования. Государства должны выразить согласие на компетенцию Комиссии и самостоятельно инициировать проведение ею расследований.

2. В работе Комиссии не действует принцип гласности, обеспечивается конфиденциальность отчетов и процесса оказания добрых услуг.

3. Состав Палаты может быть полностью сформирован на основе соглашения сторон. При проведении расследований в Палату входят члены ad hoc, которые назначаются самими сторонами конфликта.

4. Состязательность процесса установления фактов. Стороны вправе делать замечания в отношении собранных Комиссией доказательств, а также оспаривать их.

5. Компетенция оказывать добрые услуги, которые являются одним из способов разрешения международных споров.

6. Расходы на проведение расследований покрывают сами стороны.

Приведенные характеристики Комиссии свидетельствуют о том, что ее роль в международном правопорядке сводится к тому, чтобы разрешать споры о фактах серьезных нарушений Женевских конвенций и Протокола, а не к тому, чтобы «называть и порицать» («name and shame») [21, Р. 15] государство-нарушителя. Характеристики, 
рассматриваемые самой Комиссией как преимущества [21, Р. 18], на самом деле ее недостатки, дезавуирующие ее роль в обеспечении выполнения МГП.

II. Государства не заинтересованы в услугах Комиссии по разрешению их споров о фактах.

Комиссия не функционирует и в качестве органа по разрешению споров о фактах. То, что недостаточное их число признало ее компетенцию [7, Р. 489] - далеко не главная проблема, ведь даже 76 государств, которые сделали это, не обращаются к ней (для сравнения: 71 государство признало юрисдикцию Международного Суда ООН по аналогичному основанию) [9]. В основе бездействия лежит нежелание сторон конфликта «искать правду» о предполагаемых нарушениях [11, Р. 215].

Кроме того, деятельности Комиссии свойственны те же недостатки, что и международному правосудию: громоздкость и отсутствие необходимой для урегулирования конфликта гибкости методов [25, С. 677-678]. Одновременно расследованиям не присущи высокие стандарты судопроизводства, которые бы обеспечивали соблюдение прав соответствующих государств [22, Р. 174]. Отчеты о проделанной работе не содержат правовой аргументации, в которой могут нуждаться спорящие государства.

\section{Заключение}

В заключение следует отметить, что идея постоянно действующего органа по установлению фактов является значимой и весьма перспективной для обеспечения выполнения норм международного права. Однако пример Международной гуманитарной комиссии по установлению фактов обнажает затруднительность практической реализации данной идеи. Комиссия является функционально несовершенным органом. Задуманная как механизм обеспечения выполнения МГП, она, тем не менее, стала частью системы разрешения споров. Функции Комиссии более соответствуют «гроцианской» модели международных обязательств, нежели чем «кантианской» $[6$, Р. 21, 336], [28, С. 16]. Она действует в интересах отдельных государств, находящихся в конфликте, но не в интересах международного сообщества. Содействовать выполнению МГП Комиссия в силах лишь постольку, поскольку стороны конфликта принимают меры в отношении друг друга на основе ее доклада. Остальные государства, ООН и другие международные организации остаются вне данного процесса.

Для того чтобы Комиссия стала реально действующим и эффективным механизмом, требуется ее реформирование. Ключевое изменение состоит в том, чтобы привести принципы ее организации и деятельности в соответствие с целью. Для этого необходимо привнести элемент субординации в проведение расследований - за счет возможности Совета Безопасности ООН принимать обязательные для государств-членов решения. Важно наладить взаимодействие Совета Безопасности и Комиссии, установить порядок и правовые основы такого взаимодействия, а также самой деятельности по расследованию нарушений МГП. Другие органы OОН также должны принимать участие в этом процессе. Следует обеспечить гласность в работе Комиссии. Отчеты по итогам расследований должны быть открытыми для ознакомления. Следует ограничить или вовсе устранить принцип состязательности сторон в процессе установления фактов. Оказание добрых услуг должно быть изъято из компетенции Комиссии. Доработки требуют и иные положения. Необходимо правовое закрепление привилегий и иммунитетов членов Палаты, права Комиссии расследовать нарушения, совершенные в период немеждународных вооруженных конфликтов, обязанности государств обеспечивать доступ Палате и обязанности сотрудничать с ней и т.д. 


\section{Библиография:}

1. Устав Организации Объединенных Наций (принят в г. Сан-Франциско 26.06.1945) // Сборник действующих договоров, соглашений и конвенций, заключенных СССР с иностранными государствами, Вып. ХІІ, - М., 1956, с. 14-47.

2. Дополнительный протокол к Женевским конвенциям от 12 августа 1949 года, касающийся защиты жертв международных вооруженных конфликтов (Подписан в г. Женеве 08.06.1977) // Действующее международное право. Т. 2. - М.: Московский независимый институт международного права, 1997. С. 731-792

3. Резолюция Генеральной Ассамблеи ООН от 16.12.2009 № 64/121 [Электронный ресурс] // Организация Объединенных Наций [Офиц. сайт]. URL: http:/www.un.org/ru/documents/ods.asp?m=A/RES/64/121

4. Регламент Международной гуманитарной комиссии по установлению фактов (Rules of the International Humanitarian Fact-Finding Commission) [Electronic resource] // The International Humanitarian Fact-Finding Commission [Official website].URL:http://www.ihffc.org/index.asp?page=rules_of_commission, (accessed 20.04.2015)

5. Bothe M., Partsch K.J., Solf W.A. New rules for victims of Armed Conflict. Martinus Nijhoff Publishers, 1982. $747 \mathrm{p}$.

6. Cassese A. International law. Oxford University Press, 2005. 558 p.

7. Compliance with International Humanitarian Law: The International Humanitarian Fact-finding Commission // Criminal Law Forum. 1996. Vol. 7, № 2. P. 485-493

8. de Preux J. Article 90 International Fact-Finding Commission // Commentary on the Additional Protocols of 8 June 1977 to the Geneva Conventions of 12 August 1949 / ed. Y. Sandoz, C. Swinarski, B. Zimmermann, International Committee of the Red Cross and Martinus Nijhoff, 1987. P. 1037-1052

9. Declarations Recognizing the Jurisdiction of the Court as Compulsory [Electronic resource] // International Court of Justice [Official website]. URL: http://www.icj-cij.org/jurisdiction/index.php?p1=5\&p2=1\&p3=3, (accessed 19.05.2015)

10. Garraway C. Fact-finding and the International humanitarian fact-finding commission // Quality Control in Fact-Finding / ed. M. Bergsmo, Torkel Opsahl Academic EPublisher, 2013. P. 427-446

11. Kalshoven F. The International humanitarian fact-finding commission: a sleeping beauty? // Humanitäres Völkerrecht - Informationsschriften. 2002. Vol. 4. P. 213-216

12. Keith K. International humanitarian fact-finding commission: its potential // Australian Journal of Human Rights. 1999. Vol. 5. P. 101-108

13. Kunduz: MSF delivers petition calling for investigation into hospital attack [Electronic resource] // Médecins Sans Frontières (MSF) [Official website]. URL: http://www.msf.org/article/kunduz-msf-delivers-petition-calling-investigation-hospital-attack, (accessed 21.12.2015)

14. Kunduz: Updated death toll - 42 people killed in the US airstrikes on Kunduz hospital [Electronic resource] // Médecins Sans Frontières (MSF) [Official website]. URL: http://www.msf.org/article/kunduz-updated-deathtoll-\%E2\%80\%93-42-people-killed-us-airstrikes-kunduz-hospital, (accessed 21.12.2015)

15. Kussbach E. The International Humanitarian Fact-Finding Commission // International and Comparative Law Quarterly. 1994. Vol. 43, № 1. P. 174-185

16. Marauhn T. Sailing close to the wind: Human Rights Council fact-finding in situations of armed conflict - the case of Syria // California Western International Law Journal. 2013. Vol. 43, № 2. P. 401-459

17. Members of the International humanitarian fact-finding commission [Electronic resource] // the International humanitarian fact-finding commission [Official website]. URL: http://www.ihffc.org/index.asp?page=members, (accessed 22.04.2015)

18. Mokhtar A. Will this mummification saga come to an end? The International humanitarian fact-finding commission: article 90 of Protocol 1 // Pennsylvania State International Law Review. 2003. Vol. 22, № 2. P. 243-311

19. Report of the International Fact-Finding Commission 1991 - 1996 [Electronic resource] // the International humanitarian fact-finding commission [Official website]. URL: http://www.ihffc.org/index.asp?page=public_reports\&listfilter $=$ off, (accessed 20.03.2015)

20. Report of the International Humanitarian Fact-Finding Commission $1997-2001$ [Electronic resource] // the International humanitarian fact-finding commission [Official website]. URL: http://www.ihffc.org/index. asp?page $=$ public_reports\&listfilter $=$ off, $($ accessed 20.03.2015) 
21. Report on the work of the International Humanitarian Fact-Finding Commission (2006) [Electronic resource] // the International humanitarian fact-finding commission [Official website]. URL: http://www.ihffc.org/index. asp?page $=$ public_reports\&listfilter $=$ off, (accessed 20.03.2015)

22. Rosenne S. The perplexities of modern international law. Martinus Nijhoff Publishers, 2004. $471 \mathrm{p}$.

23. States Parties of the International humanitarian fact-finding commission [Electronic resource] // the International humanitarian fact-finding commission [Official website]. URL: http://www.ihffc.org/index. asp?Language $=$ EN\&page $=$ statesparties_list\&listfilter $=$ off, $($ accessed 26.04.2015)

24. Буше-Сольнье Ф. Практический словарь гуманитарного права / Пер. с франц. Е. Кирпичниковой и В. Садитдиновой. - Изд. 2-е, доп. и расширенное. - М.: МИК, 2008. 640 с.

25. Давид Э. Принципы права вооруженных конфликтов: Курс лекций, прочитанных на юридическом факультете Открытого Брюссельского университета. М.: Международный Комитет Красного Креста, 2011. $1141 \mathrm{c}$.

26. Лукашук И.И. Функционирование международного права / И.И. Лукашук. - М.: Наука, 1992. 222 с.

27. Международное право: Учебник / Под ред. Г.И. Тункина. - М.: Юрид. лит., 1994. 512 с.

28. Толстых В.Л. Курс международного права: учебник / В.Л. Толстых. - М.: Волтерс Клувер, 2010. 1056 с.

29. Толстых В.Л. Международный Суд Организации Объединенных Наций // Институты международного правосудия: Учеб. пособие / Под ред. В.Л. Толстых. - М.: Международные отношения, 2014. С. 122-144

\section{References (transliterated):}

1. Bothe M., Partsch K.J., Solf W.A. New rules for victims of Armed Conflict. Martinus Nijhoff Publishers, 1982. $747 \mathrm{p}$.

2. Cassese A. International law. Oxford University Press, 2005. 558 p.

3. de Preux J. Article 90 International Fact-Finding Commission // Commentary on the Additional Protocols of 8 June 1977 to the Geneva Conventions of 12 August 1949 / ed. Y. Sandoz, C. Swinarski, B. Zimmermann, International Committee of the Red Cross and Martinus Nijhoff, 1987. P. 1037-1052

4. Declarations Recognizing the Jurisdiction of the Court as Compulsory [Electronic resource] // International Court of Justice [Official website]. URL: http://www.icj-cij.org/jurisdiction/index.php?p1=5\&p2=1\&p3=3, (accessed 19.05.2015)

5. Garraway C. Fact-finding and the International humanitarian fact-finding commission // Quality Control in Fact-Finding / ed. M. Bergsmo, Torkel Opsahl Academic EPublisher, 2013. P. 427-446

6. Kalshoven F. The International humanitarian fact-finding commission: a sleeping beauty? // Humanitäres Völkerrecht - Informationsschriften. 2002. Vol. 4. P. 213-216

7. Keith K. International humanitarian fact-finding commission: its potential // Australian Journal of Human Rights. 1999. Vol. 5. P. 101-108

8. Kunduz: MSF delivers petition calling for investigation into hospital attack [Electronic resource] // Médecins Sans Frontières (MSF) [Official website]. URL: http://www.msf.org/article/kunduz-msf-delivers-petition-calling-investigation-hospital-attack, (accessed 21.12.2015)

9. Kussbach E. The International Humanitarian Fact-Finding Commission // International and Comparative Law Quarterly. 1994. Vol. 43, № 1. P. 174-185

10. Marauhn T. Sailing close to the wind: Human Rights Council fact-finding in situations of armed conflict - the case of Syria // California Western International Law Journal. 2013. Vol. 43, № 2. P. 401-459

11. Mokhtar A. Will this mummification saga come to an end? The International humanitarian fact-finding commission: article 90 of Protocol 1 // Pennsylvania State International Law Review. 2003. Vol. 22, № 2. P. $243-311$

12. Rosenne S. The perplexities of modern international law. Martinus Nijhoff Publishers, 2004. $471 \mathrm{p}$.

13. Bushe-Sol'n'e F. Prakticheskii slovar' gumanitarnogo prava / Per. s frants. E. Kirpichnikovoi i V. Saditdinovoi. - Izd. 2-e, dop. i rasshirennoe. - M.: MIK, 2008. 640 s.

14. David E. Printsipy prava vooruzhennykh konfliktov: Kurs lektsii, prochitannykh na yuridicheskom fakul'tete Otkrytogo Bryussel'skogo universiteta. M.: Mezhdunarodnyi Komitet Krasnogo Kresta, 2011. $1141 \mathrm{~s}$.

15. Lukashuk I.I. Funktsionirovanie mezhdunarodnogo prava/ I.I. Lukashuk. - M.: Nauka, 1992. 222 s. 
DOI: $10.7256 / 2226-6305.2016 .2 .17346$

При цитировании этой статьи сноска на doi обязательна

Международные организации и развитие отдельных отраслей мпП/ International organizations and development of specific branches of international public law

16. Tolstykh V.L. Kurs mezhdunarodnogo prava: uchebnik / V.L. Tolstykh. - M.: Volters Kluver, 2010. 1056 s.

17. Tolstykh V.L. Mezhdunarodnyi Sud Organizatsii Ob"edinennykh Natsii // Instituty mezhdunarodnogo pravosudiya: Ucheb. posobie / Pod red. V.L. Tolstykh. - M.: Mezhdunarodnye otnosheniya, 2014. S. 122-144 